\title{
Tocar y trastocar una mirada a nuestra cultura del cuerpo
}

Sintesis:

El texto presenta los avances de investigación del proyecto Imágenes de cuerpo y sexualidad de los jóvenes bogotanos, adelantado por la carrera de Comunicación Social y Periodismo de la Universidad Central. En este avance se presenta un cruce de los hallazgos de la revisión del estado del arte y las reflexiones realizadas a la luz de la mirada arqueológica de las prácticas de cuerpo, realizada a través de la revisión de investigaciones sobre el cuerpo en la Conquista y

la Colonia latinoamericanas. Este trabajo recoge el espíritu transdisciplinar en una conexión con algunos postulados de la fisica de Einstein, en tanto pregunta por el cuerpo. La reflexión sobre el cuerpo está orienta a comprender nuestras tendencias de sensibilidad, afectividad y expresión, como sujetos culturales.

Palabras clave: cuerpo, sexualidad, poder, jóvenes.

\section{Synthesis:}

The text presents the fact-finding progress of the project Body Images and sexuality of young people from Bogota, made by the faculty of

Social Communication's and Journalism from

the Central University. The text encounters a crossing of the findings of the revision of the art status and the reflections accomplished in the light

of the archeological look of the body practices, accomplished through the revision of investigations about the body in the Latin-American conquest and colony. This work gathers the spirit between disciplines in a connection with some of Einstein's physics postulates, related to questions about the body. The reflection about the body is guided to understand our tendencies of sensibility, affectivity and expression, as cultural subjects.

Key Words: The body, sexuality, power, youth.
Nina Alejandra Cabra Ayala Docente investigadora, especialista en Comunicación Educación y magister en Filosofía. e-mail: ninacabra72@yahoo.com

Un afecto no puede ser reprimido ni suprimido sino por medio de otro afecto contrario, y más fuerte que el que ha de ser reprimido.

Baruch Spinoza

El amor se comporta como lo hace Dios: ambos se entregan sólo a su servidor más valiente.

Carl G. Jung

\section{Pensar el lugar que ocupa la pregunta por el cuerpo y los afectos en la vida contemporánea, implica reconocer que "en el ámbito de las pasiones se juega la construcción de la biografía en su doble sentido: en lo que toca al mundo de lo íntimo y personal $y$, en lo que se vincula con el mundo de lo público"l. El cuerpo y los afectos se configuran como escenarios de tensión, de crisis y de transformación de las relaciones de poder, de las}

'REGUILLO, Rosanna, citada por RODRÍGUEZ ZEYDA, Paradojas del amor romántico, Relaciones amorosas entre jóvenes, Centro de investigación y estudios sobre juventud, México, 2006, Pág 13. 


\section{Megicarciones}

formas de expresión, de los regímenes de sensibilidad y de racionalidad, así como de las formas de constitución de la subjetividad. En nuestro contexto, es urgente iniciar el reconocimiento, la comprensión y la transformación de nuestra cultura del cuerpo, que nos permitan la posibilidad de ingresar en formas vitales, de buen trato y cuidado de sí.
Eneste sentido, este texto nos presenta los hallazgos preliminares de la investigación Imágenes de cuerpo y sexualidad de los jóvenes bogotanos, adelantado por la Carrera de Comunicación Social y Periodismo de la Universidad Central. Cabe señalar que la orientación metodológica está inspirada en el hecho de que, en la sociedad contemporánea, la producción de sentido se instala en los microrrelatos e imágenes y se abre en múltiples focos locales que dan voz a los actores anónimos de la vida cotidiana.

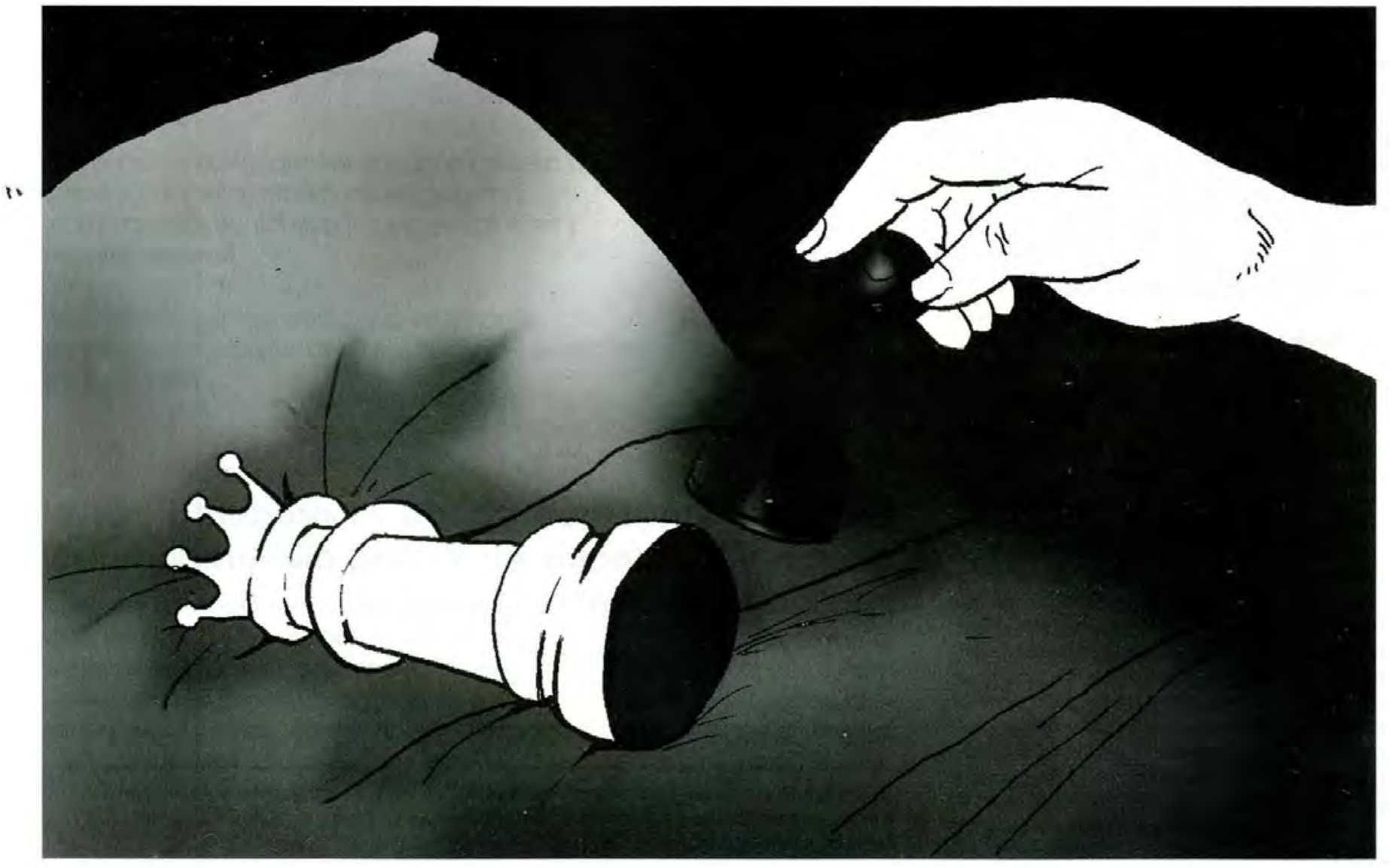


En términos de investigación, esta fase preliminar implica la revisión del estado del arte, cruzada y contrastada con la revisión arqueológica de las prácticas de cuerpo y sexualidad configuradas durante la Conquista y la Colonia latinoamericanas. Este cruce de información tiene por objetivo visibilizar los orígenes y las construcciones históricas de las prácticas de cuerpo. Se espera que la siguiente fase de la investigación nos muestre las tendencias de sensibilidad que orientan y dinamizan las prácticas de cuerpo y sexualidad de nuestros jóvenes bogotanos.

Nuestro país enfrenta serias dificultades relacionadas con los altos niveles de violencia sobre el cuerpo en distintos tópicos: violencia intrafamiliar, violencia política, que desemboca en atentados continuos contra la

" vida y la integridad del cuerpo social y de los cuerpos individuales. En lo relacionado con la sexualidad, enfrentamos una crisis que se manifiesta en las cifras de contagios de enfermedades de transmisión sexual, indices de embarazos no deseados entre adolescentes, índices de maltrato infantil, de mujeres y jóvenes en el escenario familiar. Todos estos elementos se pueden asumir como parte de la sexualidad, que no se agota en la práctica sexual, sino que se puede definir como "un artificio y una construcción sociocultural que depende, tanto del trabajo sobre el yo, como de las intervenciones gubernamentales y civiles que proveen al proceso formativo de cauces de inculcación y expresión, así como de atributos y capacidades" ${ }^{\prime 2}$.

Desde esta perspectiva, la definición de la sexualidad nos inscribe en las formas de relación que prefiguran

${ }^{2}$ REGUILLO, Rosanna y otros, Tiempo de híbridos, Entresiglos México-Cataluña, México, Instituto Mexicano de La Juventud,

Cataluña Secretaria General de Joventut, Colección Jóvenes, núm. $14,2004$. la sensibilidad que dan paso a las relaciones y encuentros de cuerpo en un contexto social determinado. "En este sentido, el asunto sobre el que se discute consiste en el proceso de subjetivación mismo, el cual incluye una concepción sobre el propio cuerpo, la manera como es experimentado y las formas de sentir y manifestar los afectos ${ }^{3}$. Las formas del sentir y sus expresiones dan forma a las prácticas culturales que attaviesan la vida cotidiana. Así, el cuerpo se configura como un lugar de visibilización de nuestras formas de ser y hacer en el mundo.

\section{Ser corporal}

Pensarnos desde la lógica del cuerpo implica el reconocimiento esencial de que hacemos parte de la naturaleza, nuestro cuerpo es su manifestación viva. Esta es una de las consideraciones elementales de cualquier forma de pensamiento que desborde la razón ilustrada. Pensarnos desde el cuerpo es percibir nuestros temblores, nuestras sensaciones, nuestra intima resonancia de fuerzas que son afines con nosotros, que nos alimentan y nos permiten conservar y afirmar nuestra vida.

El cuerpo es una densidad de experiencias, de impulsos y descargas en continuo movimiento: lo corpóreo es el sedimento de múltiples capas imperceptibles, energía que se cohesiona en tomo a ciertos núcleos sensibles, a ciertos epicentros de afinidad. Los cuerpos son tan disímiles como las formas de energía: síquica, atómica, emocional, eléctrica, anímica, cinética, y todas las demás que no somos capaces de percibir. Un cuerpo es el resultado de las combinaciones entre las diversas formas de energía que logran distintos niveles de cohesión o de consistencia.

3|bid, RODRIGUEZ, Zeyda, Paradojas del amor romántico, pág. 21. 
Cuando la física se hace la pregunta por la forma en que se puede afectar un cuerpo, es decir, ¿cómo se pueden alterar las relaciones de movimiento y reposo que lo constituyen?. Einstein nos dice que al alterar una particula inmersa en un medio determinado, esta acción afecta otras partículas y al medio en el que se encuentran. Una parfícula trasmite su movimiento al medio en el que se encuentra, alterando a las demás particulas generando cambios de densidad en el medio. En relación con el medio se puede decir: "Las partículas que lo constituyen ejecutan sólo pequeñas vibraciones, pero el movimiento integral resultante es el de una onda progresiva. El asunto esencialmente nuevo aquí es que por vez primera estamos considerando el movimiento de algo que no es materia, sino energía 1. que se propaga a través de la materia"4.

Desde esta perspectiva, los sentimientos y las pasiones (ya desde Freud reconocidos como energía anímica o libidinal) pueden ser pensados como una onda que se propaga, que se consolida o que se dispersa. La consideración del cuerpo desde la perspectiva del movimiento implica que los códigos de valoración cambian. Para Newton la fuerza de un cuerpo dependía de su masa, mientras que para Einstein la fuerza de los cuerpos depende de la velocidad, sobre todo para los cuerpos que pueden sobrepasar la velocidad de la luz. Pero ¿qué velocidad tiene la ira, la sorpresa, la alegría, o el pensamiento de un descubridor? Los cuerpos pueden pensarse a partir de la energía que los atraviesa y los mueve. Como la onda de viento que mueve cada espiga y remueve todo el sembrado.

En el caso que nos ocupa, los niveles de consistencia del cuerpo llamado Latinoamérica, tienen que ver

"EINSTEIN, A., INFELD, L., La fisica aventura del pensamiento, Editorial Losada, Buenos Aires. 1996, pág. 91. con la composición de afectos y sentimientos que lo atraviesan y animan. Pensar la Conquista y la Colonia como un encuentro de cuerpos, nos enfrenta no al gran relato de la imposición y la dominación, sino a los relatos de los microcosmos afectivos, de las pasiones y los sentimientos que se dieron cita en este choque de cuerpos.

\section{Tras-tocar al otro}

El encuentro de cuerpos desata toda la violencia de la transmutación. El choque de diversas velocidades y fuerzas es esencialmente violento. Todos los cuerpos involucrados en el encuentro sucedido en la configuración de América, blancos, negros e indigenas, sufrieron profundas transformaciones $y$ mutuas donaciones y asaltos. En este choque se mueve una densa maraña de sentimientos y pasiones que tomarán su lugar en la nueva composición resultante de este encuentro. Tal vez es en este nivel, donde se verifican los procesos de resistencia y de fuerza más importantes en este acontecimiento fundador.

Aparentemente, el encuentro de estos tres cuerpos (blanco, negro e indigena) fue una invasión que destruyó todo vestigio de las culturas dominadas. El gran relato de la conquista presenta al invasor como un actor dominante y ambicioso que sólo sentía desprecio por negros e indigenas. Pero la llamada Conquista puede pensarse como un movimiento múltiple de seducción, atravesado por distintos niveles de simulacro y de poder.

En la composición de afectos de los españoles había una extraña mezcla de atracción, temor, deseo y culpa. y un amor latente, clandestino y siempre negado por la condición misma del dominador. "Entre los aspectos más impactantes para los españoles estaba el mismo medio 


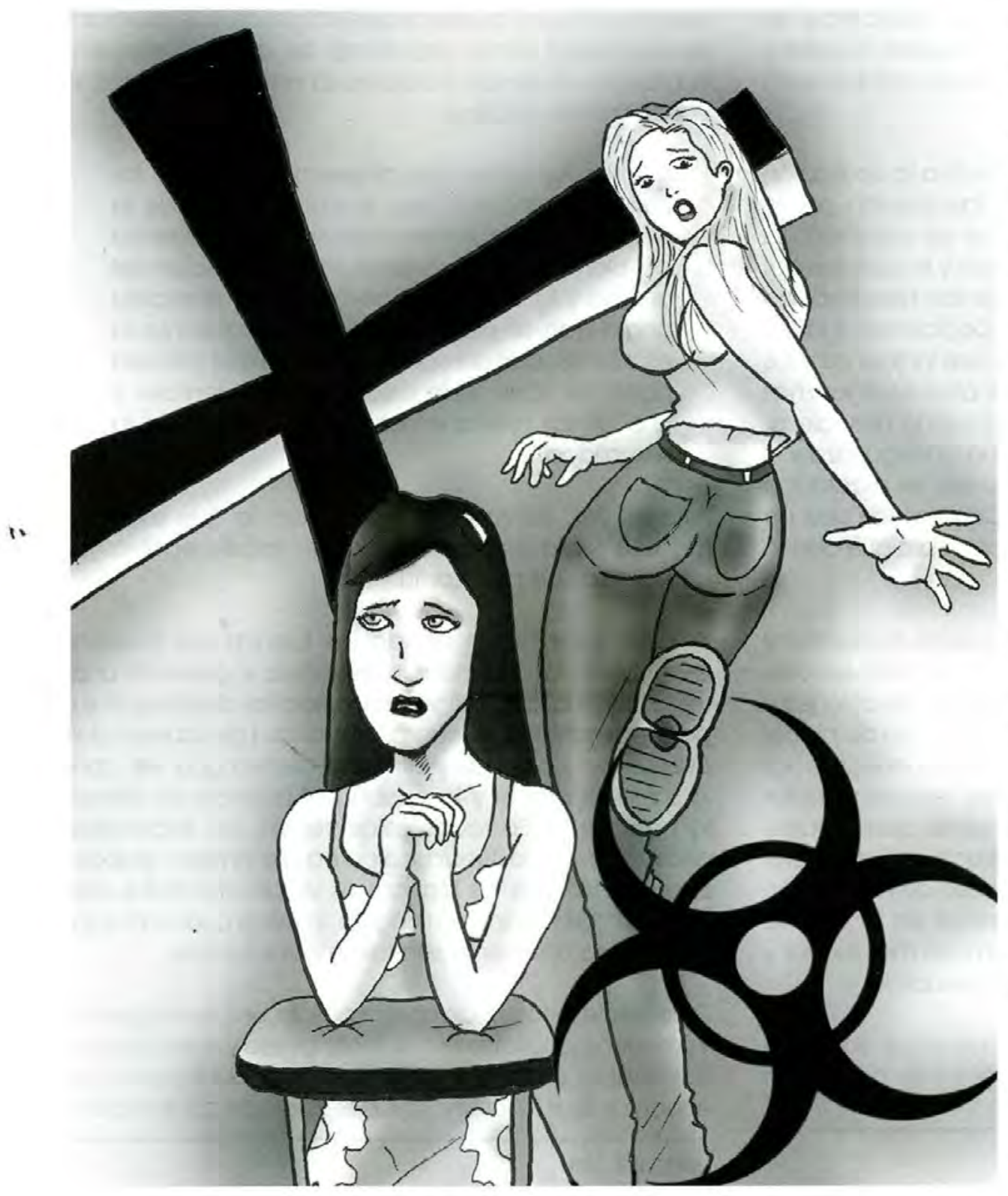

físico. Las extensas regiones que se abrían a su paso produjeron una extraña fascinación, que estaba acompañada por el temor a las novedades del camino" ${ }^{\prime \prime}$, fascinación que era avivada por la extrañeza ante animales nunca vistos, ante mujeres de rasgos desconocidos y exuberantes y ante una riqueza insospechada en distintos planos de la vida.

El descubrimiento es la experiencia vital de fondo que se mueve en este encuentro. Descubrir la diferencia, lo otro que se configura como el desorden hecho carne, como la conjugación de elementos desconocidos que excitan la curiosidad y el temor. "Cuando la Europa del siglo XV se abrió a los descubrimientos, apareció el miedo a lo lejano, a lo insólito, donde lo extraño era la regla. Este miedo se escudaba detrás de las creencias legendarias y de las exageraciones enloquecedoras que no eran más que el miedo a un universo diferente al propio"6.

${ }^{5} B O R J A$, Jaime $H_{\text {., Inquisición, muerte }}$ y sexualidad, Ceja-Ariel, Santafé de Bogotá, 1996, pág. 95. Ibid., págs. 114-115. 
Y este miedo es el elemento que exacerba la fascinación, que hace peligrosa la atracción. Ocultar y velar este temor es la estrategia necesaria del supuesto dominador.

Yes en el cuerpo donde se hace efectiva la ocultación del miedo y el despliegue de la fascinación por lo exuberante y desconocido. Es en el ser corpóreo de cada cultura donde radica el peligro y la esencia del nuevo cuerpo mestizo. Los españoles son herederos de la tradición cristiana y de la visión Occidental dualista que escinde el cuerpo y el espíritu. Los indígenas y los africanos asumían el cuerpo desde otros códigos más cercanos a la magia y a su vínculo con la naturaleza. "La desnudez del cuerpo despertaba la vergüenza y el pudor de los españoles, lo que, a su vez, les recordaba el pecado original en el paraíso. Cubrirlos fue una de las primeras disposiciones de la corona para que anden como hombres razonables" ${ }^{\prime 7}$.

Asi se inaugura una experiencia del cuerpo excitada por la contradicción. La sensibilidad corporal abría vectores de tensión que se movían en distintas direcciones y tomaban diversos sentidos. La noción misma de placer era un punto clave de distinción y encuentro de los cuerpos. Los sabores, olores, colores, texturas, sonidos y sensaciones, a los que eran sensibles cada grupo, eran distintas pero mutuamente atractivas. Este factor fue el detonante del inevitable proceso de hibridación y mestizaje. $Y$ la experiencia corporal en la que se expresan la diferencia y la atracción con más fuerza, $y$ que da paso al nuevo cuerpo es la sexualidad.

La experiencia de cuerpo se instalaba sobre la contradicción dualista del español y la condición

\footnotetext{
${ }^{7}$ Ibid., pág. 192.
}

corpórea integral de africanos e indígenas, que asumian su sexualidad como una forma de relacionarse con el mundo y la tenían incorporada en su experiencia y conocimiento mágico.

"De fondo, había una diferencia más bajo los principios Occidentales, la comprensión de la sexualidad estaba orientada hacia el problema del bien y del mal, es decir, la identificación del cuerpo y la sexualidad con el mal, y el espíritu con el bien. Se pretendía, fundamentalmente, la espiritualización del cuerpo, principio que formaria parte del acervo de creencias Occidentales y uno de los mecanismos para el control de la sexuallidad"s.

Pero tal vez, de manera paradójica, lo que sucedió fue una lenta encarnación de lo imperceptible, la corporallzación del espíritu.

Y es en este punto donde las fuerzas del cuerpo descentran la dominación española y generan una relación en la que indígenas y africanos despliegan su poder de afectar el cuerpo español. Los saberes del cuerpo de indígenas y africanos tienen que ver con la salud, el placer y la posibilidad mágica de alterar la naturaleza. En todos estos frentes, los españoles cedieron ante la fuerza corpórea de ambos grupos. El hecho de que los blancos se vieran afectados por estas formas de acción mágica, implica que su propio cuerpo era altamente sensible a estas fuerzas.

El aparente esfuerzo de control de los cuerpos indigenas y africanos, ocultaba el creciente deseo y la excitación del cuerpo español, que lentamente cedía ante los encantos de sus dominados. El ejercicio de control sobre

${ }^{a}$ Ibid., pág. 195. 
indios y negros implicaba el contacto con sus cuerpos y entonces, dicho ejercicio "paradójicamente alimentó el ardor de los colonos. La ausencia real de sistemas de control frente a éstos favoreció su acelerado proceso de desinhibición" ${ }^{\prime \prime}$. En este punto la desinhibición no es otra cosa que la lenta liberación de un cuerpo que se había paralizado, que se había congelado por los rigores de una moral que reprimia las fuerzas vitales del deseo.

Así se verifica el poder del cuerpo. Las crónicas de la Colonia son ricas en textos que relatan las innumerables relaciones clandestinas que involucraban españoles con negras e indias. La pasión del blanco se vio exacerbada por las actifudes de negros e indígenas frente a la sexualidad y a su cuerpo. Desde los grandes conquistadores como Cortés, hasta los funcionarios y los colonos españoles, se vieron presa de amores clandestinos, que los sorprendían y los torturaban por la contravención de normas que los sentimientos y la pasión hacian cada vez más difusas.

\section{La herejía o el saber del cuerpo}

Por otro lado, los negros y los indigenas tenían fuertes tradiciones de conocimiento mágico. Esta forma de conocer se basa en la creencia, el contacto y la interacción con una fuerza sobrenatural inmanente a la naturaleza. Este conocimiento implica la participación de las fuerzas naturales para movilizar y transformar la naturaleza misma. La magia es la forma de conocimiento que integra el cuerpo, la intuición y la sabiduría de las sensaciones. Todos estos escenarios de conocimiento eran deslegitimados y condenados por la tradición cristiana y por la naciente forma del pensamiento racional ilustrado.

Ibid. pág. 80 .
Esta forma de conocimiento fue otro de los elementos que permitió a negros e indios afectar a los españoles y ejercer su poder para trastocarlos. "Los esclavos, por ejemplo, les enseñaron a los blancos a temerles: los españoles tenían miedo de los poderes sobrenaturales de los negros como lo demostró la proliferación de acusados por ejercer brujería, herbolaria o hechicería con fines amatorios en el siglo XVII"10. Asi mismo, encontramos diversas referencias que nos permiten afirmar que la naturaleza silenciosa de los indigenas generaba el mismo temor entre los españoles, quienes habian probado el conocimiento indigena de los poderes sanadores de las hierbas, pero también de sus posibilidades en el uso de venenos poderosos.

El sentimiento de la amenaza constante por fuerzas desconocidas y temibles, era un elemento que angustiaba y enfurecía a los españoles. De la fascinación al temor el cuerpo blanco se agitaba y se aceleraba. La atracción y fascinación del español, se mezclaba con el desprecio por formas de vida que consideraba salvajes y diabólicas, era este factor el que desataba altos niveles de hostilidad entre todos los actores de esta colonia contradictoria. "Esta hostilidad estaba justificada por su mismo comportamiento, en un rescoldo de sus conciencias debian saber que sus acciones sólo podian producir rencor en las llamadas castas. Para hacer una historia de los españoles en América, tendríamos que hacer una historia del miedo al otro"II.

En este punto, el temor estaba fuertemente vinculado con los poderes del otro cuerpo y con el reconocimiento tácito y silencioso de las fuerzas ocultas en el saber

\footnotetext{
10 Ibid., pág. 182.
}

${ }^{11}$ CEBALLOS G, Diana, Hechiceria, brujería e inquisición e el Nuevo Reino de Granada. Un duelo de imaginarios, Editorial Universidad Nacional, Colombia, 1995, pág. 19. 


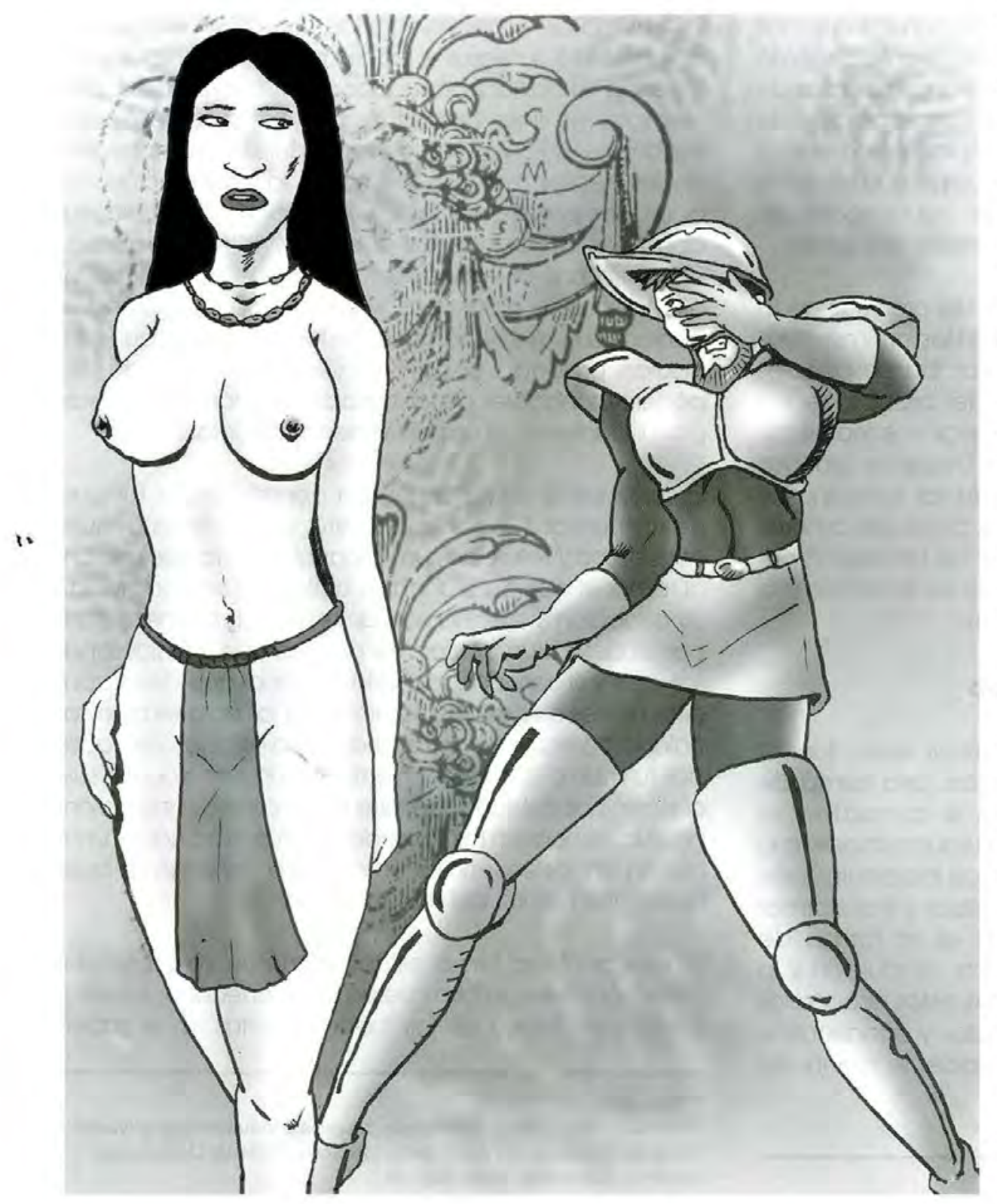

mágico de los indígenas y de los africanos. El saber mágico de estos dos grupos era altamente temido pero indudablemente, también altamente consultado por los españoles. Los registros de la Inquisición muestran una alta frecuencia de procesos relacionados con artes amatorias, adivinatorias y de sanación. El saber mágico fue permeando la vida cotidiana de manera subrepticia, contando con la complicidad de todos. Este fenómeno fue denominado por varios curas y cronistas de la Colonia como el contagio diabólico, que contaminaba y trastocaba el buen juicio de los hombres.

Es importante señalar que este contagio y las formas de control de la sexualidad dirigieron todo su rigor hacia las mujeres, en especial a las mujeres africanas, quienes eran nombradas brujas por su poder maléfico sobre los hombres. Esta situación tiene origen en el profundo impacto que tiene la cultura de cuerpo de los africanos, expresada en danzas rituales, cercanías y formas de contacto mucho más abiertas y flexibles que las de los indigenas y españoles. El contagio sensual era el gran temor de los españoles, que lentamente se 
iban mezclando, dando origen a un mestizo confundido y atravesado por la contradicción dolorosa y violenta de un constante movimiento de atracción y repulsión. La consecuencia de esta contradicción es el miedo al ser tocado y trastocado por el cuerpo del otro.

\section{La transmutación de los afectos}

Como rastro doloroso de este choque de cuerpos nos ha quedado una mezcla de miedo y desprecio que nos paraliza, que nos resta fuerza y nos entristece. Porque el real desafuero de la Colonia fue desatar una guerra en la que el miedo era el veneno más tóxico. "Se trataba de jugar con el miedo del otro para alejarlo de su territorio [...] se inauguraba, sin duda, una mutua "cultura del terror". Cada uno desde sus simbolos azuzaba al otro, ya fuera para mantener el control sobre un territorio o para conquistarlo"12

El miedo mezclado con el desprecio por el otro generará una situación dificil para el mestizo, pues el desprecio que sentían unos por otros, blancos, negros e indios, se sintetiza para convertirse en desprecio por si mismo. Cuando el mestizo mezcla en su propio cuerpo los residuos del desprecio del blanco por el negro y viceversa, lo que termina sucediendo es que el mestizo desprecia al tiempo su componente blanco y negro, lo que termina siendo el drama de una contradicción dolorosa que se ha prolongado por muchas generaciones.

Este núcleo de sentimientos y afectos reducen nuestra potencia de actuar y nos mantienen en una cierta parálisis. Lo grave de esta parálisis no es tanto que no

12BORJA GÓMEZ, Jaime, Rostros y rastros del demonio en la Nueva Granada, Santafé de Bogotá, Ariel Historia, 1998, pág. 69. podamos movernos, sino que no podamos percibirnos como un cuerpo en el que convergen fuerzas de tres naturalezas distintas que se han encontrado para darle paso a lo nuevo de la vida y para generar distintas formas de ser y de hacer en el mundo.

\section{Los cuerpos jóvenes}

En lo relacionado con los jóvenes contemporáneos, la pregunta por el cuerpo y la sexualidad se hace mucho más sensible, en términos de ser un escenario en el que convergen distintas problemáticas y tendencias sociales.

"El tema de la sexualidad juvenil resulta el nodo de disputa más intenso en el campo simbólico del cuerpo y la afectividad. Analizando las confrontaciones que ocurren en este terreno se manifiesta de manera nítida el proceso social que define cuales son las fronteras entre lo correcto y lo incorrecto, lo normal y anormal, lo adecuado e inadecuado para la etapa de juventud. En el se traslucen igualmente las visiones sobre el placer y el uso del cuerpo que se disputan la hegemonia para definir la moral para la sociedad en su conjunto"13.

En el estado del arte encontramos que la noción de subjetividad se encuentra como fundamento de la mayoria de las investigaciones revisadas. El interés de rastrear y conocer las formas en que los esquemas corporales de percepción, apreciación y acción. dinamizan la vida de los individuos y conforman las prácticas colectivas son el punto de partida de la investigación en este campo. El enfoque teórico

\footnotetext{
${ }^{13}$ Ibidem, pág. 141.
} 
predominante en los proyectos de investigación sobre el cuerpo y la sexuallad de los jóvenes es el posestructuralismo, con un fuerte énfasis en los planteamientos que hace Foucault. Este origen teórico determina la marcada tendencia a asumir el cuerpo como una construcción cultural histórica. Esta perspectiva, "lejos de pensar que el cuerpo consiste únicamente en el asiento biológico y fisiológico de las personas, parte de la idea de que es un ámbito privilegiado de poder, fenómeno que genera como afirma Michel Foucault su conversión en un objeto de saber y de disputa"14.

Esta orientación implica una tendencia recurrente a registrar las prácticas de cuerpo vinculadas con formas de resistencia y de dominación. En este sentido, encontramos que los estudios sobre cuerpo en jóvenes tienen una primera gran división según la postura o relación de poder. Por un lado se habla de los llamados jóvenes integrados o institucionalizados, que se caracterizan por estar inscritos en discursos y prácticas institucionales como la familia (viven y dependen de sus padres) y la escuela (siguen procesos regulares de escolaridad). Por otro lado, encontramos los denominados movimientos o culturas juveniles, pensados como prácticas alternas o contestatarias de producción de identidades. Estos grupos son pensados desde sus expresiones sensibles y artísticas (movimientos o grupos musicales) por sus formas de afiliación afectiva a tribus urbanas y por sus usos y prácticas de cuerpo contestatarias y de resistencia al orden establecido.

Encontramos que un punto de convergencia en los estudios revisados, es la tendencia a asumir que "el cuerpo es mediación social y lugar de encuentro; con el cuerpo se trazan diferencias, distancias y se articulan

${ }^{14}$ Ibid , RODRIGUEZ, Zeyda, Paradojas del amor romántico, pág. 21. pactos y tribalidades; con el cuerpo se lee la ciudad. $Y$ es a través del cuerpo, que hombres y mujeres jóvenes construyen estrategias de visibilización social que son, en sentido estricto, fórmulas de integración ciudadana $^{\prime \prime 15}$. En este sentido, los estudios de cuerpo se configuran como un escenario para comprender las transformaciones políticas y los fondos éticos de la vida contemporánea.

Estas formas de vincularse con nuevas prácticas ciudadanas atraviesan la pregunta por el mercado y por los usos y consumos del cuerpo de los jóvenes. En relación con este punto, cabe señalar, que una corriente importante de estudios e investigaciones sobre el tema se dedican a explorar las formas discursivas de los medios masivos sobre el cuerpo y los consumos que estos discursos promueven entre los jóvenes. Esta tendencia de trabajo plantea como interrogante central el diseño del cuerpo y sus tecnologías y formas de expresión. Una de las conclusiones capitales en este terreno nos indica que los discursos mediáticos aparecen como expresiones y prácticas de control que configuran un clerto tipo de cuerpo. "A las viejas formas de vigilancia panóptica les corresponde un cuerpo casto, castrado y culposo. A las nuevas formas de vigilancia panóptica les corresponde un cuerpo de la salud y la obsesión por las formas de inmunización. Cuerpo paranoico e hipocondríaco"16.

Sin embargo, resulta significativo, como se ha señalado anteriormente, el que se haya generado un reconocimiento generalizado de las implicaciones políticas y las posibilidades transformadoras de los

${ }^{15}$ GÓMEZ, Rocío del Socorro, DESIGN, DESIGNAR, DISEÑAR EI cuerpo joven y urbano, Universidad del valle, Colciencias, 2003, pág. 123.

${ }^{16} \mid$ bid., pág. 124. 


\section{H}

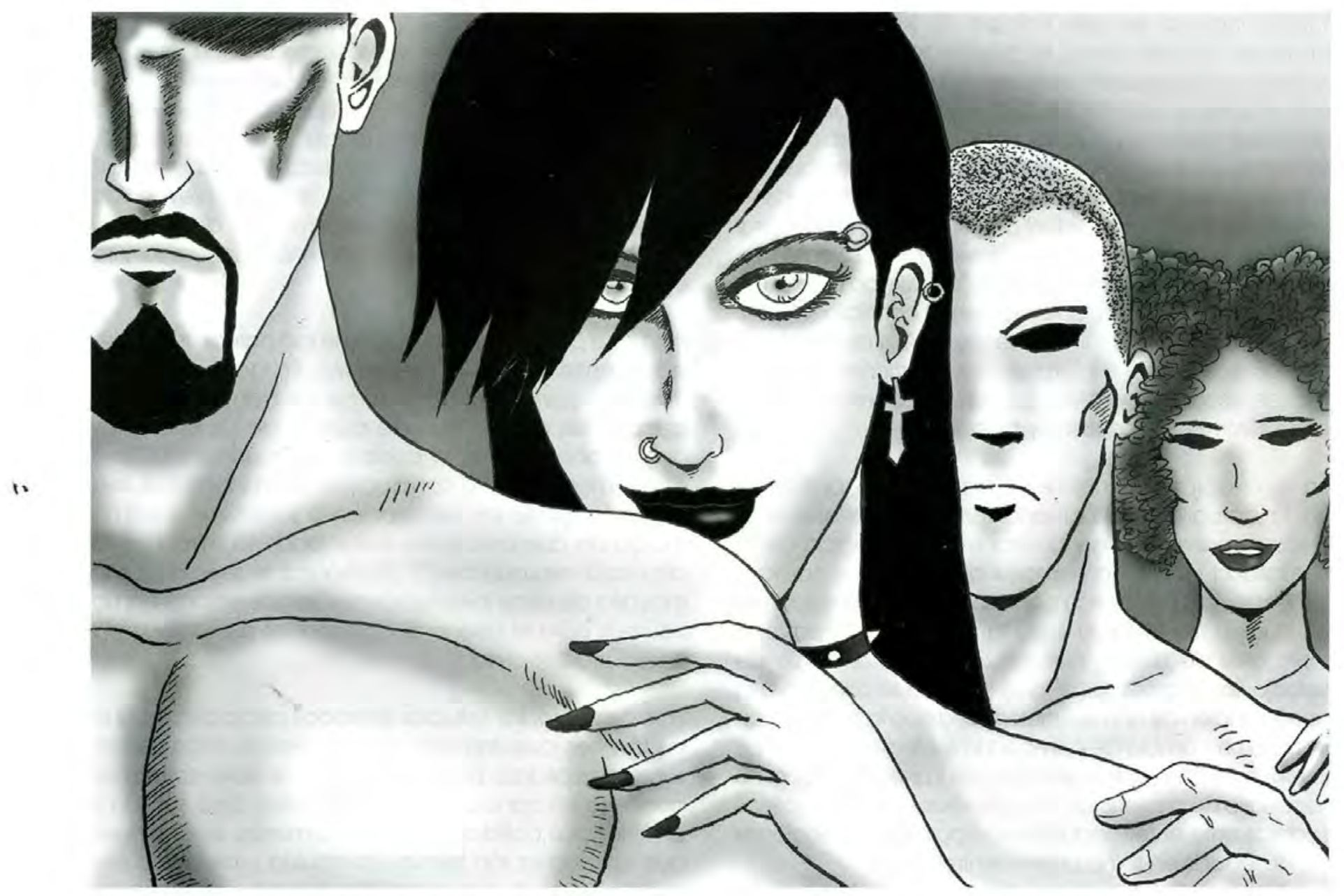

afectos y de las expresiones sensibles del cuerpo. Así, encontramos que una de las expectativas ante la dimensión afectiva es la de "experimentar la construcción, sostenimiento de otras lógicas, podrían restituir a la afectividad, al amor, al eros, una potencia articuladora, que más allá de la tragedia del héroe de Musil, posibilitaran un mundo en el que la afectividad completara mucho más que el deseo de preservar al objeto amado y la entrega a éste"17, y es desde esta expectativa que se plantea el tema de la sexualidad, como campo de significados, de encuentros y de transformación e incorporación de los afectos.

${ }^{17}$ bid., RODRÍGUEZ Zeyda, pág. 15. 
Y para ingresar en este campo de interrogantes se propone, iniclalmente, la posibilidad de iniciar la reflexión y la búsqueda entre los jóvenes de su relación con el cuerpo, una noción que nos permita articular la dimensión histórica y cultural, pero también la dimensión sensorial y sensible. Desde los planteamientos de Bourdieu y de las perspectivas sicoanalíticas contemporáneas se puede asumir la necesidad de superar las divisiones y distinciones cuerpo mente, o cuerpo inconsciente y se propone abordar la pregunta por "un cuerpo pensante; un cuerpo que habla, que expresa el conflicto síquico, que reacciona de forma inesperada, irracional; un cuerpo que recibe e interpreta percepciones olfativas, táctiles, visuales y auditivas que tejen sutilmente vinculos entre sufrimiento, angustia y placer" ${ }^{\prime \prime}$,

En lo relacionado con este campo, encontramos en la actualidad una fuerte tendencia a asumir el discurso preventivo de control epidemiológico de la sexualidad juvenil. Ya hemos indicado antes como a las formas del panóptico contemporáneo corresponde un cuerpo de la salud y de la paranoia por posibles contagios de distinta naturaleza. Para este frente de trabajo, los saberes sobre la sexualidad se orientan a la configuración de una ecuación en la que la información implica un cambio de comportamiento sexual entre los jóvenes. En este sentido se habla de la sexualidad como escenario de prevención y de construcción de prácticas seguras ante enfermedades contagiosas o situaciones no deseadas en torno al encuentro sexual.

Por otro lado, encontramos que los estudios sobre el lugar que ocupa el cuerpo en la vida social de los jóvenes, tiene otro giro importante que tiene que ver con la sexualidad como "factor de crisis y determinante

"1'LAMAS, Marta, Cuerpo, diferencia sexual y género, pág.156. del comportamiento juvenil. En general el tema de la sexualidad, el género y el cuerpo parece interesar más por sus consecuencias en la salud pública o en los problemas de orden social, que por la necesidad de aclarar nociones relacionadas con intimidad, cuidado de sí mismo y afectividad"19. Esta línea de trabajo asume la pregunta por las formas de prevención de enfermedades y embarazos no deseados, inscribiendo la sexualidad en la esfera del riesgo y la epidemiologia.

Para esta perspectiva "Ia corporalidad parece reducirse a la genitalidad o el embarazo. En general, en las investigaciones registradas no se contempla una perspectiva amplia que dé cuenta de las diferentes dimensiones donde el cuerpo hace presencia, sea como medio para la construcción de la identidad, sea como locus de las percepciones subjetivas o como medio de comunicación, reduciendo la mirada a la dimensión reproductiva"20. Es importante señalar que la mayoría de estas investigaciones se referencian como insumos para el diseño de campañas preventivas y/o de educación sexual.

En este punto, los estudios revisados coinciden en que los jóvenes cuentan con altos niveles de información sobre sexualidad, pero muy poco de este acervo se convierte en conocimiento significativo para su vida y experiencias cotidianas. Adicionalmente, se concluye que la información formal (construída y circulada por la escuela, instituciones y entidades gubernamentales de prevención y salud sexual) no tiene suficiente fuerza o calado entre los jóvenes como para transformar los

19SERRANO, J.F., y otros, Juventud. Estado del arte, Bogotá 1990 - 2000, Departamento Administrativo de Acción Comunal del Distrito, Bogotá, 2003, pág. 90 .

20lbid, pág. 92. 
imaginarios que se forman con fuerza a partir de las fuentes menos formales y documentadas sobre el tema (los medios masivos, los grupos de amigos, los padres). De esta forma, la información informal logra mayor incidencia en la composición de imaginarios y prácticas relacionadas con el cuerpo y la sexualidad de los jóvenes.

La mayor preocupación que motiva este tipo de trabajos encontrados en distintos países de Latinoamérica es que "las campañas educativas por los medios de comunicación no conducen a la modificación masiva del comportamiento sexual, [...] y que a los actores es necesario proponerles opciones diversas del amplio espectro del placer sexual de manera que éstas no se reduzcan sólo a las prácticas sexuales tradicionales, muchas veces sesgadas por los convencionalismos ortodoxos" ${ }^{\prime 21}$

Otro elemento abordado por la investigación en este campo es la tipificación de fuentes de conocimiento $e$ información a las que recurren los jóvenes en la construcción de su sexualidad.

"Resulta así que los jóvenes encuentran su curiosidad sexual inmersa en un juego de fuerzas que jalan, desde distintos epicentros, hacia el control y castigo moral por parte de los padres, la información parcial y genitalizada por parte de la escuela y los profesionales de la salud, los estereotipos sexuales dominantes por parte de los medios de comunicación masiva, en especial la televisión, y la producción de mitos, tabúes e información desvittuada por parte de los propios grupos de pares ${ }^{\prime 22}$.

\footnotetext{
${ }^{2}$ REGUILLO, Rosanna y otros, Op. cit., pág, 57
}

${ }^{22}$ lbidem, pág. 64.
Yen medio de este cruce tan conflictivo, los jóvenes no encuentran la opción de construir su sexualidad como una práctica del goce y del disfrute del propio cuerpo y del cuerpo del otro.

\section{Contagium: los cuerpos híbridos}

Ya desde la Conquista se incorporó un núcleo de afectos contradictorios que integra el temor, el deseo, la fascinación y el desprecio, el amor y el resentimiento. Resulta altamente significativo que tanto en los cuerpos coloniales, como en los cuerpos jóvenes contemporáneos, se registra un fuerte temor al contagio. En la Colonia el temor era por el contagio diabólico, por la transmisión de demonios y fuerzas descontroladas y salvajes que desbordaban al otro y lo transformaban, haciéndolo igualmente salvaje y desmesurado. En la actualidad, el temor es que ese desafuero genera un cuerpo promiscuo que se expone al contagio de enfermedades altamente temidas.

La necesidad de controlar y de generar las llamadas prácticas seguras, es una constante que se registra desde la Colonia, sólo que han variado los ejes sobre los que gira dicho control. De igual manera, se registran movimientos de resistencia y de fuerzas que se sustraen al control, y que abren nuevos cursos corporales. Los afectos que dinamizan estos cuerpos siguen moviendo nodos contradictorios que incluyen angustia y temor.

Si revisamos su raíz etimológica, encontramos que el término contagio, viene del latín contagium, de contingere que significa tocar con contaminación, contaminar. Y si revisamos el significado esencial de la contaminación es la transformación de un cuerpo por contacto directo o indirecto, la transformación de una esencia como resultado de una mezcla. El contagio es el trastocamiento de los cuerpos. Dejar de ser algo para transformarse en una nueva forma. 


\section{Areglearciones}

Si volvemos a la reflexión que nos aportó Einstein al inicio de este texto، podemos afirmar que el temor al contagio, no es otra cosa, que el temor de un cuerpo que se ve agitado y transmutado por una onda que lo atraviesa, que lo moviliza y lo lanza hacia otras condiciones y formas de ser. El contagio es el movimiento de las energias y afectos de los cuerpos en contacto, es la transmisión de fuerzas que inauguran seres mestizos, híbridos. Y la fuerza de la onda es correlativa a la fuerza de los cuerpos.

La constitución de nuestra sexualidad es la propagación de fuerzas sensuales de alta potencia e intensidad. Cuerpos excitados, que elevan sus fuerzas en el tocarse, el placer y el temor de la transmutación. Pero así como crece y se elevan el amor, el deseo y

" la pasión, aumentan sus correlatos de culpa, temor y angustia. Si bien es cierto que tienen nombres distintos y. aparentemente, tienen orígenes diferentes, seguimos en el esquema del bien y del mal, del temor al castigo por el desborde de la pasión y de los placeres del cuerpo. Para los cuerpos de la Colonia el castigo provenía del demonio y para los cuerpos contemporáneos viene de virus y bacterias que son igualmente implacables $y$ aterrorizantes.

Yen esta propagación de ondas afectivas y de sentido, emergen nuevas pasiones, afectos alterados e híbridos, tendencias y gustos que desbordan las polaridades femenino - masculino, bien - mal, espiritu - cuerpo, amor - odio. Las hibridaciones corporales generan hibridaciones afectivas que se expresan de diversas formas. El conocimiento de las tendencias sensibles y de las posibilidades de afectar otros cuerpos nos inscribe en el territorio de la reconfiguración de la vida. Pues, si bien es cierto que el cuerpo se constituye como el lugar del control, también es el escenario de la vida misma. "Más allá de las sujeciones, en nuestro cuerpo habita la contingencia de re-crear la vida, de transmutar identidades inamovibles en subjetlivaciones con diversos sentidos vitales"23.

Y es en la vida afectiva donde esta posibilidad cobra fuerza, en donde se guardan los lenguajes y las formas de comunicación que pueden transformar nuestra cultura del cuerpo y del afecto, para ingresar en formas del cuidado y del buen trato de si mismo y del otro. En medio de esta reflexión es urgente reconocer que las prácticas de cuerpo y las formas de encuentro deben encontrar una salida a los nodos de angustia y culpa, de rabia y resentimiento, heredados de tiempos ya lejanos.

En este orden de ideas, la comunicación supera el intercambio de información y se asume como un traspaso de fuerzas, como una afectación de cuerpos que transforman la vida. $Y$ si el contagio es una forma de encuentro que nos marca desde hace tanto tiempo, podemos pensar en una perspectiva afirmativa del trastocamiento. Pues así como se propagan ondas de miedo y de angustia, podemos poner en movimlento fuerzas que sanen estos cuerpos atemorizados y paranoicos.

Desde esta perspectiva, el desafío ético de la comunicación es generar encuentros que nos ayuden a soltar el cuerpo, a liberarlo de las angustias y los temores. Si nos atrae y fascina el otro, la diferencia y somos seres corporales, ya es tiempo de superar la culpa y el desprecio. Y es importante considerar si la explosión de campañas "preventivas" no genera un efecto angustiante, que activa los nodos de temor latentes en nuestro cuerpo.

23. bid., ESCOBAR, Manuel R., pág. 232 
El tema de la prevención implica una negación, una acción movida por el temor. Y tal vez las prácticas de cuerpo implican de por sí, el gran y atractivo riesgo del trastocamiento. Entrar en el discurso de las prácticas seguras, aumenta la confusión y las contradicciones de nuestros jóvenes. En este punto, encontramos que el temor al contagio implica sentidos profundos. En el fondo de la idea de la contaminación habita el fantasma latente de la idea atávica de pureza. Y este tipo de discursos genera la angustia de la pérdida de la pureza del cuerpo, bien sea en el tema racial, sexual, espiritual o social.

En el fondo de nuestros temores late la pretensión ya inútil de preservar una pureza que va en contravía de nuestro ser híbrido, Y los temores, tristezas y angustias del cuerpo pueden ser afectadas y transformadas si en nuestras prácticas logramos recuperar la alegría y la fuerza vital del cuerpo. Las fuerzas del baile, del abrazo, de la caricia, de la donación de fuerzas que nos ayudan a salir de la violencia y el maltrato. Es urgente resignificar nuestros códigos de cuerpo y darle eco a las voces de nuestros ancestros que vivan en la certeza de que el cuerpo es el lugar sagrado en el que se maniflesta la vida. [D]

\section{Bibliografia}

BARBERO, Jesús M., "Arte comunicación tecnicidad en el fin de sigio", en Ensayo y Error, año 3, núm. 5, octubre 1998.

EINSTEIN A. Infeld L., La física aventura del pensamiento, Buenos Aires, Editorial Losada, 1996.

BORJA GÓMEZ, Jaime, Rostros y rastros del demonio en la Nueva Granada, Santafé de Bogotá, Ariel Historia, 1998.

BORJA, Jaime $H_{\text {. }}$ Inquisición, muerte y sexualidad, Santafé de Bogotá, Ceja-Ariel, 1996.

CEBALLOS G., Diana., Hechicería, brujería e Inquisiciónen el Nuevo Reino de Granada. Un duelo de imaginarios, Bogotá, Editorial Universidad Nacional, Colombla, 1995.

ESCOBAR Cajamarca, Manuel Roberto y otros, Agrupaciones, culturas juveniles y escuela en Bogotá, -Estudio piloto- Informe final (mimeo) IESCO-Universidad Central, Secretaría de Educación Distrital SED, Bogotá, 2005, 181 págs.

GÓMEZ, Rocio del Socorro, DESIGN, DESIGNAR, DISEÑAR El cuerpo joven y urbano, Cali, Universidad del Valle - Colciencias, 2003.

GUADARRAMA G., Pablo., Humanismo y autenticidad en el pensamiento filosófico latinoamericano,

http://www.cenit.cult.cu/sites/revista islas/pdf/128 08 Guadarrama.pdf

JULIÁN, Antonio, Monarquía del diablo en la genitilidad del Nuevo Mundo Americano, Bogotá, Instituto Caro y Cuervo, 1994. 
LAMAS, Marta, Cuerpo, diferencia sexual y género, México, Taurus, 2002.

LYOTARD, Jean Francois, La posmodernidad explicada a los niños, Barcelona, Gedisa, 1996.

MUN̄OZ, Germán, "Contexto histórico de la comunicacióncultura en Colombia", en Boletín de Carrera, núm. 2. Proyecto Académico de Carrera, Comunicación Social Periodismo, Universidad Central, 2006.

REGUILLO, Rosana y otros, Tiempo de híbridos, Entresiglos México-Cataluña, México, Instituto Mexicano de la Juventud, Cataluña Secretaria General de Joventut, 2004.

1. RODRígueZ, Zeyda, Paradojas del amor romántico. Relaciones amorosas entre jóvenes, México, Centro de investigación y estudios sobre juventud, 2006.

SALLES-REESE, Verónica (Editora), Repensando el pasado, recuperando el futuro: nuevos aportes interdisciplinarios para el estudio de la América colonial, Bogotá, Universidad Javeriana, 2005.

SERRANO, J.F., y otros, Juventud. Estado del arte. Bogotá 1990 - 2000, Bogotá, DIUC-Departamento Adminiștrativo de Acción Comunal del Distrito, 2003.

SPINOZA, Baruch, Ética, Alianza editorial, Madrid, 2001.

SPLENDIANI, Anna María; Sánchez B., José E; Luque de S., Emma $C_{\text {. }}$ Cincuenta años de Inquisición en el Tribunal de Cartagena de Indias: 1610-1660, Bogotá, Centro Editorial Javeriano, Instituto Colombiano de Cultura Hispánica, 1997. 